\title{
SELECTION OF A TEXTILE BINDER APPLICATION METHOD FOR
}

\section{A NEW TEXTILE PROCESS}

\section{ALEXIA PARDO FIGUEROA, OSCAR F. TORO \& BRIGITTE M. LARICO}

Dirección De Investigación, Instituto De Energía Y Medio Ambiente, Universidad Católica San Pablo, Arequipa, Perú

ABSTRACT
The textile sector has been developing new alternative textile processes, which need to increase the performed
research in this area, for the identification of optimal methodologies for the manufacture of textile products with specific
technical characteristics. This research presents the procedure used for the selection of a textile binder application
methodology, relevant process in the manufacturing of non-woven textiles. This method has to assure the formation of a
homogenous and consistent film of binder over the fibers that permits the application of subsequent processes. The
following application methods were evaluated: (1) Pistol-pistol, (2) sheet-pistol and (3) submersion.
KEYWORDS: Application Method, Textile Binder, Methodology, Pistol, Sheet \& Submersion

Received: Nov 22, 2017; Accepted: Dec 12, 2017; Published: Jan 06, 2018; Paper Id.: IJTFTFEB20181

\section{INTRODUCTION}

Non-woven textiles are characterized for being plain sheets obtained through the consolidation of fibers or filaments, which can be interlaced mechanically, thermally or chemically, without going through textile traditional spinning and weaving processes. (INDA, 2017). The application of this textile genre is reduced in the textile industry due to the empirical development of new alternative textile processes. In this situation, a new research for the technification of a new non-woven textile process; which can work with animal, vegetal and synthetic fibers; is being developed. For the adequate cohesion and compaction between fibers, a textile binder (a substance capable of adhering to the fibers and form a film over them) is used (Lockuan, 2012). On a previous research, the optimal textile binder (Arkofil) was selected, being this a polyvinyl alcohol polymer with medium viscosity (Toro, Pardo Figueroa \& Larico, 2017) and (Achroma Management LLC, 2014). However, the need for the selection of the optimal application methodology arose, one which will be able to completely cohere the fibers for subsequent processes, without any impairment or delay.

The determination of the three methods selected for the laboratory tests (pistol-pistol, sheet-pistol and submersion) were made based on interviews with experts. The pistol-pistol method carried out using a textile degumming gun whose function is the dispersion of the textile binder uniformly in both sides of the sheet of fiber. The sheet-pistol method, which also uses the degumming gun, is carried on by applying the textile binder over a formed sheet (fibers covered by a polyester hollow fabric called can-can) so it can impregnate the fibers through it. Lastly, the submersion methodology consists of submerging the fiber sheet in a recipient filled with textile binder, and applying a slight manual pressure over the textile sheet so it absorbs the binder.

The selection of this methodology requires the performance of test that assure the validity of the results. The objective of this research was to determine the most optimal methodology for the application of the textile 
binder, through an election based on experimental laboratory tests.

\section{METHODOLOGY}

\section{Considerations}

For the determination of the optimal application methodology, pilot tests were performed having in account the following considerations:

- 04 different kinds of combed fibers were used: baby alpaca, coarse alpaca, acrylic and jute.

- Textile sheets of $20 \times 20$ centimeters were formed as representative samples of the product of the new textile process.

- According to the information gathering and the expert consulting, three methodologies were proposed for evaluation: pistol-pistol, sheet-pistol and submersion.

- For the evaluation of the three proposed methodology, a matrix was formed considering three representatives samples for each kind of fiber, having a total of thirty six $20 \times 20$-fiber sheets.

- According to the information gathering and the expert consulting, it was determined that the controlled variables during the productive process were the following: kind of fiber, preparation time $1(\mathrm{~s})$, assembly time (s), initial weight $(\mathrm{g})$, quantity of textile binder $(\mathrm{ml})$, textile binder application time (s), textile binder drying time (s), weight with textile binder (g), time of application of the non-woven technique (s), weight after the technique (g), textile binder removing time (s), weight with water $(\mathrm{g})$, final drying time $(\mathrm{s})$ and final weight $(\mathrm{g})$.

- The characteristics of the degumming gun can be seen in table $\mathrm{N}^{\circ} 01$.

- The characteristics of the textile binder can be seen in table $\mathrm{N}^{\circ} 02$.

- Three factors were considered for the selection of the application methodology: cycle time, quantity of textile binder and fiber behavior.

Table 1: Technical Specifications of the Degumming Gun

\begin{tabular}{|c|l|l|}
\hline \multicolumn{2}{|c|}{ Textile degumming pistol } \\
\hline Name & Arrow Spray Gun & \\
\hline Model & $\mathrm{YH}-170$ \\
\hline Weight allowed & $1.2 \mathrm{~kg}$ to $1.7 \mathrm{~kg}$ & \\
\hline Voltage & $220 \mathrm{~V}$ \\
\hline
\end{tabular}

Source: data sheet

Table 2: Arkofil Technical Specifications

\begin{tabular}{|c|l|}
\hline \multicolumn{2}{|l|}{ Arkofil } \\
\hline Appearance & White \\
\hline Physical state & Granulated \\
\hline Ionic character & Non-ionic \\
\hline Ph & $4.5-7(4 \%$ active on neutral water $)$ \\
\hline Fusion temperature & $160-200^{\circ} \mathrm{C}$ \\
\hline Boiling temperature & $400^{\circ} \mathrm{C}$ \\
\hline Density & $1.25 \mathrm{~g} / \mathrm{cm}^{3}\left(20^{\circ} \mathrm{C}\right)$ \\
\hline Water solubility & Soluble a $20^{\circ} \mathrm{C}$ \\
\hline
\end{tabular}


Source: data sheet

\section{Pilot Tests}

The tests consisted of assembling textile sheets with coarse alpaca, baby alpaca, jute and acrylic fibers, apply the textile binder, submit them to the non-woven production process and remove the textile binder from the non-woven fabric obtained.

\section{Pistol-Pistol Methodology}

\section{Assembly}

The raw material was prepared and $20 \times 20$ sheets of fiber were made, controlling 04 variables: kind of fiber, preparation time (time in seconds for the preparation of the jute fibers, for this fibers were acquired as ropes and must be frayed for them to be suitable for the process), assembly time and initial weight.

\section{Textile Binder Application}

\section{Pistol-pistol}

This stage consists in the application of Arkofil for the temporal cohesion of the fiber sheet obtained in the assembly, using the pistol described in table $\mathrm{N}^{\circ} 1$. The application is made in both sides of the sheets controlling 02 variables: quantity of textile binder and application time. (pistol-pistol)

\section{Sheet-pistol}

This stage consists in the application of Arkofil for the temporal cohesion of the fiber sheet obtained in the assembly by using can-can surfaces over which the textile binder is applied with the pistol described in table 1 . This application is done on both sides of the textile sheet controlling 02 variables: quantity of textile binder and application time.

\section{Submersion}

This stage consists of the application of Arkofil for the temporal cohesion of the fiber sheet obtained in the assembly, by placing the sheets inside a plastic tray and pouring the liquid Arkofil over them until they are completely wet. During this test 02 variables were controlled: quantity of textile binder and application time.

\section{Textile Binder Drying}

Once the textile binder has been applied, the textile sheets are introduced into a dryer until they completely dry. In this stage, 02 variables were controlled: textile binder drying time and weight with textile binder.

\section{Application of the Non-Woven Technique}

Having the compact $20 \times 20$ centimeters sheets of fibers, they are subject to the non-woven technique. The sheets obtained in the last process must have uniform surfaces for this process to be optimal. The controlled variables are time of application of the non-woven technique and weight after the technique.

\section{Textile Binder Removal}

This stage consists of the elimination of the textile binder from the cohered textile sheet, by using water to wash it off. To do this process firstly the sheet is left soaking in water for ten minutes, then it is softly squeezed and spin-dried, and 
finally it is left to dry. Once the textile sheet has dried the excess loose fiber from the borders is removed (cut with scissors). The controlled variables in this process are textile binder removing time, weight with water, final drying time and final weight.

The results of the tests with the different textile binder applications can be seen in table $\mathrm{N}^{\circ} 03$

Table 3: Results Table

\begin{tabular}{|c|c|c|c|c|c|c|c|c|c|c|c|c|c|c|}
\hline \multicolumn{15}{|c|}{ Results table } \\
\hline Technique & Fiber & $\begin{array}{l}\text { Preparation } \\
\text { time (s) }\end{array}$ & $\begin{array}{c}\text { Assembly } \\
\text { time (s) }\end{array}$ & $\begin{array}{c}\text { Initial } \\
\text { weight } \\
\text { (gr) }\end{array}$ & $\begin{array}{c}\text { Quantity } \\
\text { of textile } \\
\text { binder } \\
\text { (ml) }\end{array}$ & $\begin{array}{c}\text { Textile } \\
\text { binder } \\
\text { application } \\
\text { time (s) }\end{array}$ & $\begin{array}{c}\text { Textile } \\
\text { binder } \\
\text { drying } \\
\text { time } \\
\text { (s) }\end{array}$ & $\begin{array}{l}\text { Weight } \\
\text { with } \\
\text { textile } \\
\text { binder } \\
\text { (g) }\end{array}$ & $\begin{array}{c}\text { Time of } \\
\text { application } \\
\text { of the non- } \\
\text { woven } \\
\text { technique } \\
\text { (s) }\end{array}$ & $\begin{array}{c}\text { Weight } \\
\text { after the } \\
\text { technique } \\
\text { (g) }\end{array}$ & $\begin{array}{l}\text { Textile } \\
\text { binder } \\
\text { removing } \\
\text { time (s) }\end{array}$ & $\begin{array}{l}\text { Weight } \\
\text { with } \\
\text { water } \\
\text { (g) }\end{array}$ & $\begin{array}{c}\text { Final } \\
\text { drying } \\
\text { time (s) }\end{array}$ & $\begin{array}{c}\text { Final } \\
\text { weight } \\
\text { (g) }\end{array}$ \\
\hline \multirow{4}{*}{$\begin{array}{l}\text { Pistol- } \\
\text { pistol }\end{array}$} & $\begin{array}{l}\text { Coarse } \\
\text { alpaca }\end{array}$ & - & 410.00 & 14.94 & 21.50 & 1218.33 & 7680 & 15.32 & 130 & 15.92 & 1088.93 & 17.44 & 1500 & 11 \\
\hline & $\begin{array}{l}\text { Baby } \\
\text { alpaca }\end{array}$ & - & 245.33 & 9.76 & 20.42 & 1233.67 & 7680 & 10.95 & 130 & 11.14 & 1087.62 & 12.41 & 1500 & 7.45 \\
\hline & Acrylic & - & 415.00 & 11.56 & 26.95 & 1184.67 & 6300 & 12.70 & 130 & 13.23 & 1087.75 & 14.47 & 1500 & 8.91 \\
\hline & Jute & 12636 & 1054.33 & 13.25 & 24.56 & 1305.00 & 6300 & 14.91 & 130 & 15.12 & 1090.34 & 21.43 & 1500 & 10.95 \\
\hline \multirow{4}{*}{ Sheet-pistol } & $\begin{array}{l}\text { Coarse } \\
\text { alpaca }\end{array}$ & - & 423.33 & 14.94 & 35.59 & 175.33 & 10440 & 17.30 & 130 & 17.53 & 1086.78 & 18.21 & 1260 & 10.87 \\
\hline & $\begin{array}{l}\text { Baby } \\
\text { alpaca }\end{array}$ & - & 341.33 & 9.74 & 28.06 & 177.33 & 10440 & 11.57 & 130 & 11.78 & 1084.56 & 11.81 & 1260 & 7.31 \\
\hline & Acrylic & - & 452.33 & 11.57 & 27.76 & 157.67 & 10440 & 13.45 & 130 & 13.76 & 1085.17 & 15.23 & 1260 & 9.64 \\
\hline & Jute & 12874.33 & 1057.67 & 13.29 & 36.22 & 145.33 & 10440 & 15.77 & 130 & 16.10 & 1084.51 & 21.80 & 1260 & 10.32 \\
\hline \multirow{4}{*}{ Submersion } & $\begin{array}{l}\text { Coarse } \\
\text { alpaca }\end{array}$ & - & 376.33 & 14.95 & 50.93 & 383.33 & 11220 & 18.78 & 130 & 18.99 & 1088.63 & 19.74 & 1260 & 10.40 \\
\hline & $\begin{array}{l}\text { Baby } \\
\text { alpaca }\end{array}$ & - & 279.33 & 9.78 & 29.33 & 356.00 & 11220 & 12.12 & 130 & 12.36 & 1088.60 & 14.00 & 1260 & 7.45 \\
\hline & Acrylic & - & 464.67 & 11.54 & 46.67 & 168.67 & 11220 & 14.77 & 130 & 16.67 & 1089.13 & 14.88 & 1260 & 8.43 \\
\hline & Jute & 12708 & 1040.00 & 13.25 & 53.07 & 285.67 & 11220 & 16.76 & 130 & 18.41 & 1086.65 & 23.00 & 1260 & 10.99 \\
\hline
\end{tabular}

Source: Own elaboration

\section{RESULTS}

Having executed the process for obtaining non-woven textile for the three types of textile binder application methods, the data collected from each of them have been analyzed were obtained the following results:

- The lead-time of the pistol-pistol method is approximately 3.20 hours, the pistol-sheet method is 3.80 hours and the submersion method is 4 hours.

- The quantity of textile binder used through the pistol-pistol method is $23.36 \mathrm{ml}$ average, for the sheet-pistol method, $31.91 \mathrm{ml}$ average and for the submersion method is $45 \mathrm{ml}$ average.

- The compaction required in the textile binder application stage must reach a point where the sheet does not show any deformities during the application of the non-woven technique and the textile binder removal. In the pistolpistol methodology the fibers did not cohere completely, for there were sheets that were damaged during the nonwoven technique application; additionally, the application by both sides with the pistol caused the appearance of indentations in the sheet, which made the application of subsequent processes more difficult. The pistol-sheet methodology achieves the complete cohesion of the sheet, which was enough for it to be processed. The submersion method attained the required cohesion, but the textile sheet was deformed, obtaining a thinner and larger sheet; furthermore, it requires a greater effort in to remove the textile binder.

Table 04 shows us the factors for the selection of the methodology; and, the results in the selection of the most optimal method (sheet-pistol) were made through factor weighting, which can be seen in table $\mathrm{N}^{\circ} 05$. 
Table 4: Factor Weighting for the Selection of the Textile Binder Application Methodology

\begin{tabular}{|l|c|c|c|c|c|}
\hline \multicolumn{1}{|c|}{ Factors } & Lead time & $\begin{array}{c}\text { Quantity of } \\
\text { textile binder }\end{array}$ & $\begin{array}{c}\text { Fiber } \\
\text { behavior }\end{array}$ & Total & Weight \\
\hline Lead time & 3 & 3 & 2 & 8 & 0.30 \\
\hline Quantity of textile binder & 3 & 3 & 2 & 8 & 0.30 \\
\hline Fiber behavior & 4 & 4 & 3 & 11 & 0.40 \\
\hline Total & \multicolumn{5}{|l|}{} \\
\hline
\end{tabular}

Note: The qualification was made having in consideration the following values: 1-Much less important than, 2Less important than, 3- As important as, 4- More important than, and 5-Much more important than.

Source: Own elaboration

Table 5: Evaluation and Selection of the Methodology for the Application of Textile Binder in the NonWoven Textile Manufacturing Process

\begin{tabular}{|l|c|c|c|c|}
\hline \multicolumn{1}{|c|}{ Factors/Methodology } & Peso & Pistol-pistol & Sheet-pistol & Submerssion \\
\hline Lead time & 0.30 & 5 & 3 & 1 \\
\hline Quantity of textile binder & 0.30 & 1 & 3 & 5 \\
\hline Fiber behavior & 0.40 & 1 & 5 & 3 \\
\hline Total & $\mathbf{1 . 0 0}$ & $\mathbf{2 . 2}$ & $\mathbf{3 . 8}$ & $\mathbf{3}$ \\
\hline
\end{tabular}

Note: The qualification was made having in consideration the following values: 1- Deficient, 2- Bad, 3Standard,4-Good, and 5-Excelent.

Source: Own elaboration

\section{CONCLUSIONS}

- The textile binder application methodologies can be changed independently without drastically changing subsequent processes.

- Even though the submersion methodology reaches the necessary fiber cohesion, the deformation of the sheet of fiber during the process discards this methodology.

- The most optimal application methodology selected was the sheet-pistol method, because is lead-time and quantity of textile binder allowed us to obtain an adequate fiber cohesion, having a product without deformities.

\section{REFERENCES}

1. Association of the Nonwoven Fabrics Industry, INDA (2017). About Nonwovens. Retrieved on november 3rd, 2017 fromhttp://www.inda.org/about-inda/

2. Lockuán Lavado, F. E. (2012). La industria textil y su control de calidad, IV. Tejeduría (pp. 8-14). Retrieved on november 2nd, 2017 fromhttp://fidel-lockuan.webs.com

3. Archroma Management LLC (2014). Technical information Arkofil FVJ Gran

4. S. Jayapriya \& G. Bagyalakshmi, Textile Antimicrobial Testing and Standards, International Journal of Textile and Fashion Technology (IJTFT), Volume 4, Issue 1, January - February 2014, pp. 1-10

5. Toro, Pardo Figueroa \& Larico (2017), Methodology for the selection of Chemical Textile Products. International Journal of Textile and Fashion Technology. 
